\title{
US seeking more transparency from pharma
}

$\mathrm{T}$ he United States government is "deeply concerned" about the rising costs of drugs and is seeking greater transparency from pharmaceutical companies, states the administration's budget for fiscal year 2017.

Specifically, the budget, released Feb. 9, proposes granting the US Department of Health and Human Services the authority to "require drug manufacturers to publicly disclose certain information, including research and development costs, discounts, and other data."

"While it is hugely positive to see in plain writing the US government's request for the pharmaceutical industry's disclosure of areas, such as research and development costs it has typically kept hidden, the issue remains, how realistic is it to see these provisions translated into practice?," Jillian Clare Kohler, director of the World Health Organization Collaborative Centre for Governance, Transparency and Accountability in the Pharmaceutical Sector, wrote in an email.

Proposals for making drug pricing more transparent are already pending in seven states, according to a Feb. 25 paper in the New England Journal of Medicine. This may have little effect, however, on reducing the high costs of drugs, according to the paper's author, Rena Conti, an assistant professor, departments of pediatrics (hematology/ oncology) and public health sciences at the University of Chicago. There is no "single, easy answer to high and escalating drug prices in the United States," she wrote, noting that enhancement of market forces to pressure companies to lower prices may be more effective than policies to increase transparency.

"I view these policies as symbolic gestures, symptoms of public outrage regarding the high costs of drug-based treatment for selected diseases," Conti added in an email. "Research and development costs have nothing to do with the prices drug companies actually charge for new drugs. If the goal of this outrage is to increase patients' access to and the affordability of drug-based treat-

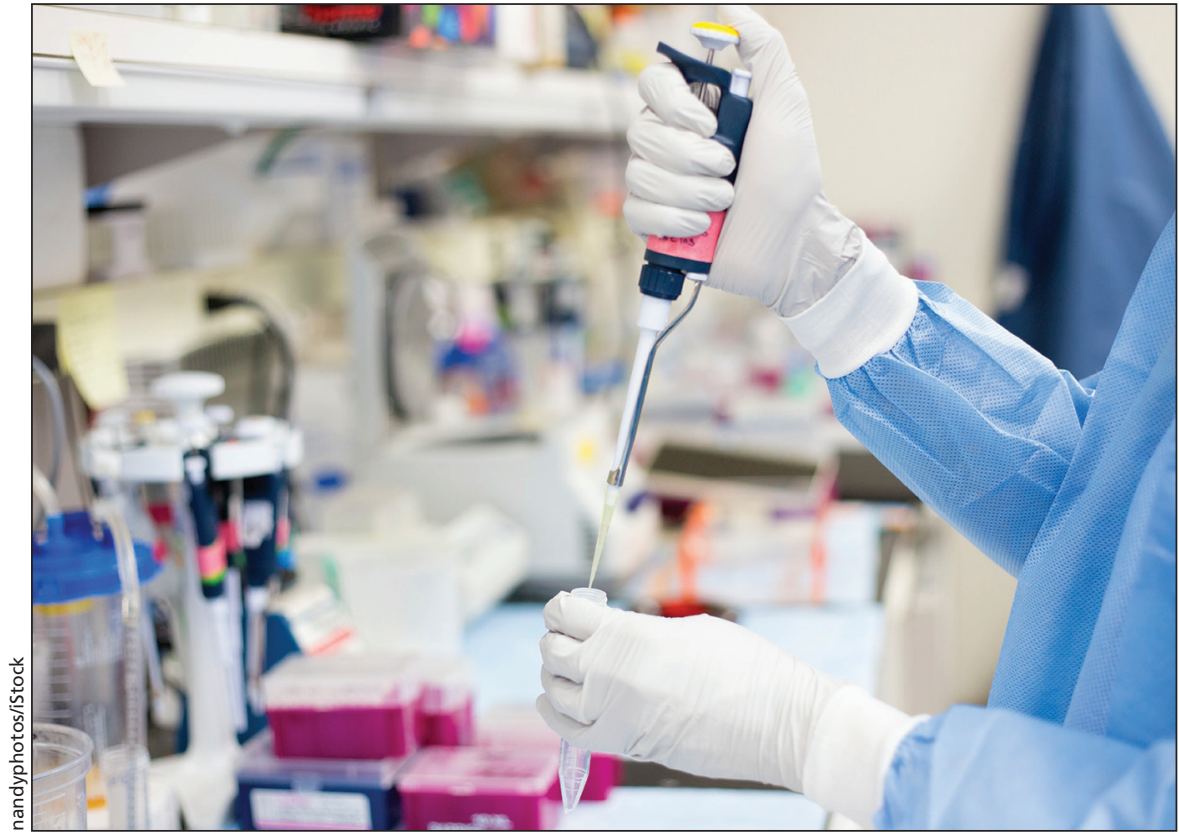

The US government has proposed that drug companies disclose their research and development costs.

ment for disease, there are more tractable policies to accomplish this goal."

Indeed, demands for the public disclosure of pharmaceutical research and development costs is a "bit of a red herring," according to Len Nichols, director of the Center for Health Policy Research and Ethics at George Mason University. "Past costs are sunk, and should have no impact on today's pricing decisions, which are all about elasticity of today's demand and production costs," Nichols wrote in an email. "All people who took Econ 101 know this. Okay, 201."

That's not to say increased transparency of drug company finances wouldn't have benefits, noted Nichols. For one, it could reveal that drug companies sometimes spend more on marketing than actual research and development. This would be useful information for policymakers in discussions about whether to regulate the percentage of resources the pharmaceutical industry should devote to developing new drugs.

But changing how US drug companies do business, including what information they disclose publicly, will likely prove difficult. Many members of the US Senate and the US House of Representatives receive campaign contributions from the Pharmaceutical Research and Manufacturers of America (PhRMA), a trade group that represents the US pharmaceutical industry, noted Nichols. "PhRMA is kind of like the NRA [National Rifle Association] in US politics: reformers have to find a way to protect members from the association's wrath for them to be willing to risk engaging in policy discussions or vote in ways that PhRMA opposes."

When asked to comment on the budget's proposal to increase transparency in the pharmaceutical sector, a media representative for PhRMA forwarded $C M A J$ a statement released on Feb. 9. It states that the government's budget includes "harmful and misguided proposals" and that "mandating public disclosure of proprietary information would undermine our competitive market-based system and incentives for innovation." - Roger Collier, CMAJ

CMAJ 2016. DOI:10.1503/cmaj.109-5245 